\title{
IMPLEMENTASI PORTAL PENGENALAN BUDAYA INDONESIA IBUDAYA.ID
}

\author{
Winarno Darmoyuwono ${ }^{1}$, Rudy Pramono ${ }^{2}$ Wella $^{3}$ \\ ${ }^{1}$ Universitas Multimedia Nasional \\ ${ }^{2}$ Universitas Pelita Harapan \\ ${ }^{3}$ Universitas Multimedia Nasional
}

pmwinarno@umn.ac.id,rudy.pramono@uph.edu,wella@umn.ac.id

\begin{abstract}
Abstrak
Permasalahan yang diangkat pada kegiatan pengabdian kepada masyarakat ini adalah tingginya krisis budaya yang dialami oleh masyarakat Indonesia, khususnya generasi muda yang lebih suka budaya luar negeri dibandingkan budaya lokal. Kegiatan pengabdian kepada masyarakat ini berusaha untuk mengubah persepsi old fashioned budaya lokal dengan cara menggabungkan budaya lokal dengan perkembangan teknologi informasi dan komunikasi yang sekarang ini sedang marak digunakan oleh masyarakat segala kalangan. Metode yang digunakan dalam kegiatan pengabdian kepada masyarakat ini adalah membuat aplikasi berbasis web ibudaya.id dan kontennya didapat dari partisipasi masyarakat (crowdsourcing) karena membutuhkan bantuan masyarakat luar untuk mengisi kontennya. Berdasarkan hasil kegiatan pengabdian kepada masyarakat ini dapat disimpulkan bahwa implementasi Portal iBudaya.id telah berhasil dilakukan. Hingga saat ini terdapat sekitar 200 user yang telah mendaftar, dan pada umumnya para user tersebut telah mengunggah konten-konten yang menarik. Seiring perjalanan waktu, dan didukung upaya-upaya promosi, diharapkan Portal iBudaya.id ini akan semakin populer dan dibutuhkan oleh masyarakat. Hasil dari kegiatan pengabdian masyarakat ini adalah bentuk portal website yang dapat dikunjungi, dan para pengunjung website juga dapat ikut berpartisipasi untuk mengunggah konten seperti video, fotografi, dan narasi.
\end{abstract}

Kata kunci: Crowdsourcing, ibudaya.id, konten, teknologi informasi dan komunikasi, Web

\section{PENDAHULUAN}

Salah satu persoalan serius sebuah bangsa adalah luntur dan terasingnya budaya aslinya dari bangsa itu sendiri. Terkait krisis budaya nusantara dewasa ini, seorang budayawan Emha Ainun Nadjib menyebut dua kelompok masyarakat Indonesia. Pertama, mereka yang gampang menjadi orang barat (kebarat-baratan). Kedua, mereka yang gampang menjadi orang Arab (kearab-araban).
Budaya bangsa kita seolah menjadi hal asing bagi bangsa kita sendiri, menjauh dari diri kita. Bangsa ini krisis budaya (Kompasiana.com, 2016). Padahal menurut Mendagri rakyat Indonesia yang pluralistik, merupakan kenyataan yang harus dilihat sebagai aset nasional, bukan risiko atau beban. Rakyat adalah potensi nasional yang harus diberdayakan, ditingkatkan potensi dan produktivitas fisik, mental, dan kulturalnya (Zonalima.com, 2016).

$$
\text { Teknologi Informasi dan Komunikasi }
$$


Menteri Dalam Negeri (Mendagri) Tjahjo Kumolo menyatakan bahwa bangsa Indonesia saat ini sedang menghadapi krisis budaya (Zonalima.com, 2016). Tambahnya, bila tidak segera ditegakkan upaya 'membentuk' secara tegas identitas nasional dan kesadaran nasional, maka bangsa Indonesia akan menghadapi kehancuran (Zonalima.com, 2016). Pendapat ini juga diperkuat lagi oleh Renita Sari Adrian, seorang pengamat budaya Indonesia. Ujarnya, Indonesia tidak memiliki tempat yang Indonesia banget di pusat Kota Jakarta, padahal Indonesia kaya dengan budaya (Liputan6.com, 2017). Begitupun dengan pendapat seorang entertainer Indonesia, Irfan Hakim. Irfan menyayangkan generasi muda yang gengsi dengan budaya asli Indonesia (Liputan6.com, 2016). Padahal budaya-budaya luar negeri sangat mudah untuk menyebar di masyarakat Indonesia, khususnya generasi muda (Liputan6.com, 2016).

Guru Besar Antropologi Universitas Diponegoro Semarang, Agus Maladi Irianto menilai teknologi informasi sangat efektif sebagai sarana politik budaya, sebagaimana dilakukan Korea Selatan (Republika.co.id, 2017). Mantan Ketua Dewan Kesenian Semarang (Dekase) tersebut menambahkan bahwa keberadaan media sosial dan televisi sekarang ini memang sangat memengaruhi banyak orang dan sudah mengubah perabadan sebagaimana kajian antropologi dulu (Republika.co.id, 2017).

Maka pengabdian kepada masyarakat ini bertujuan untuk mengimplementasikan suatu teknologi informasi dan komunikasi (TIK) yang dapat memperkenalkan, melestarikan, dan mensosialisasikan nilai-nilai budaya dan kearifan lokal, yang dapat berupa video, fotografi, juga narasi digital.

Implementasi teknologi informasi dan komunikasi ini berbentuk portal budaya yang dalam pengumpulan datanya menggunakan teknik crowdsourcing. Crowdsourcing telah menjadi paradigma yang menjanjikan untuk menyelesaikan tugas yang berada di luar kemampuan mesin melalui tugas outsourcing ke kerumunan orang secara online (Safran \& Che, 2017). Crowdsourcing telah berkembang, seperti Wikipedia dan Mekanis Turk, hingga teknik yang sekarang ini digunakan oleh perusahaan dan akademisi untuk tujuan yang berbeda (Goncalves, Hosio, Vukovic, \& Konomi, 2017). Crowdsourcing memungkinkan karakterisasi dan evaluasi kinerja yang bagus dari jaringan skala besar saat ini menggunakan kekuatan massa dan kecerdasan yang terdistribusi (Gregori et al., 2016).

Pengabdian kepada masyarakat ini berusaha untuk mengubah persepsi old fashioned budaya lokal dengan cara menggabungkan budaya lokal dengan perkembangan teknologi informasi dan komunikasi yang sekarang ini sedang marak digunakan oleh masyarakat segala kalangan.

Dengan adanya portal yang menampung nilai-nilai budaya dan kearifan lokal, maka diharapkan: 1) Nilai-nilai budaya dan kearifan lokal masyarakat di Indonesia akan dapat dilestarikan. 2) Nilai-nilai budaya dan kearifan lokal masyarakat di Indonesia akan dapat disosialisasikan. 3) Konten tentang nilai-nilai budaya dan kearifan lokal akan bertambah terus dengan partisipasi dari masyarakat. 4) Adanya apresiasi terhadap nilai-nilai budaya dan kearifan lokal masyarakat Indonesia, baik dari dalam negeri maupun luar negeri. 5) Timbulnya potensi ekonomi dari pembuatan konten multimedia, berupa video, foto, narasi, yang membuka peluang kerja.

Pengabdian kepada masyarakat ini dipandang urgent untuk dilaksanakan mengingat masyarakat Indonesia menghadapi pertarungan budaya lokal melawan budaya global. Kita tentunya memahami bahwa budaya lokal cenderung kalah melawan budaya global. Ini berarti bahwa masyarakat Indonesia diambang kehancuran nilainilai budaya, yang berarti kehancuran masyarakat Indonesia itu sendiri. Maka untuk mempertahankan eksistensi masyarakat Indonesia, diperlukan portal yang dapat menampung berbagai nilai-nilai budaya dan kearifan lokal masyarakat Indonesia.

Portal yang akan dikembangkan dalam pengabdian kepada masyarakat ini dapat mengelola konten multimedia, berupa foto, video, dan narasi. Pengelolaan file tersebut akan dilaksanakan secara crowdsourcing.Pendahuluan mencakup latar belakang atas isu atau permasalahan serta urgensi dan ra sionalisasi kegiatan. Bagian ini juga menyajikan tujuan kegiatan, dan rencana penanganan masalah, ser ta tinjauan pustaka yang relevan dan pengembangan metode penyelesaian masalah.

Teknologi Informasi dan Komunikasi 
Majchrzak \& Malhotra (2013) menemukan bahwa teknik crowdsourcing sangat efektif dan efisien dalam melibatkan para karyawan perusahaan untuk aktif memberikan ide-ide inovatif bagi perusahaan. Namun pendekatan ini memerlukan perhatian penuh dalam mendesain arsitektur sociotechnical participation. Ia menambahkan bahwa demi berjalannya teknik crowdsourcing ini, dibutuhkan elemen insentif / bonus agar meningkatkan kompetitif dalam "kerumunan" (Majchrzak \& Malhotra, 2013). Namun (Nowacki \& Bachnik, 2016) menganggap bahwa portal atau knowledge management tidaklah efektif digunakan dikarenakan lingkungan / "kerumunan" yang fluktuatif dan mengganggu. Ditentang oleh (Zhao, De Pablos, \& Qi, 2012), menuliskan bahwa knowledge management adalah isu penting bagi organisasi.

Sivula \& Kantola (2015) menyatakan bahwa crowdsourcing masih merupakan konsep yang relatif baru untuk bisnis dan sains, dan oleh karena itu memerlukan pengembangan ontologi holistik. Crowdsourcing dapat menjadi model yang berguna untuk aktivitas perusahaan dan ontologi holistik memberikan cara baru dalam mengelola operasi crowdsourcing. Oleh karena itu, crowdsourcing membutuhkan manajemen, yang dapat didasarkan pada ontologi manajemen crowdsourcing. Ontologi Crowdsourcing menyediakan delapan konsep yang dapat dimanfaatkan manajer untuk mengelola aktivitas crowdsourcing. Ontologi mencakup konsep keterbukaan, platform, manajemen, sumber daya, kompensasi, tugas, fokus, dan kedewasaan. Konsep ini mempengaruhi hasil akhir dan nilai yang diterima perusahaan dari aktivitas crowdsourcing.

(Yuan, Xi, \& Xiaoyi, 2012) melakukan studi mengenai portal web pemerintahan China dimana mereka menggunakan kerangka evaluasi baru yang berdasarkan prinsip administrasi publik kontemporer dan teori evaluasi web. Mereka menemukan bahwa perbedaan tingkat perkembangan e-government di China dan negara maju telah menyempit, namun beberapa aspek interaksi antara pemerintah dan warga negara masih dalam tahap awal.
Dapat disimpulkan bahwa portal website atau knowledge management banyak digunakan demi meningkatkan competitive advantages suatu organisasi (Von Krogh, 2012), khususnya organisasi bisnis. Mereka melibatkan pengguna / "kerumunan" untuk memberikan konten dalam portal / knowledge management mereka, bahkan agar konten terjaga dan up-to-date, para manajemen memberikan hadiah / insentif bagi mereka yang terlibat aktif.

Pendekatan ini bisa diimplementasikan juga di suatu "kerumunan" besar dimana perlu adanya manajemen yang baik dalam mengelola crowdsourcing. Karena kesuksesan metode crowdsourcing bukan dilihat dari besaran "kerumunan" yang dimiliki namun bagaimana pihak manajemen dapat mengelola "kerumunan" tersebut. Oleh karena itu, pengabdian kepada masyarakat ini menggunakan metode crowdsourcing agar konten pada portal budaya dapat ramai dan up-to-date.

Crowdsourcing telah menjadi paradigma yang menjanjikan untuk menyelesaikan tugas yang berada di luar kemampuan mesin melalui tugas outsourcing ke kerumunan orang secara online (Safran \& Che, 2017). Crowdsourcing telah berkembang, seperti Wikipedia dan Mekanis Turk, hingga teknik yang sekarang ini digunakan oleh perusahaan dan akademisi untuk tujuan yang berbeda (Goncalves et al., 2017). Crowdsourcing memungkinkan karakterisasi dan evaluasi kinerja yang bagus dari jaringan skala besar menggunakan kekuatan masa dan kecerdasan yang terdistribusi (Gregori et al., 2016).

Konsep crowdsourcing telah ada selama berabad-abad, sebuah studi baru-baru ini menunjukkan bahwa lebih dari 40 definisi yang berbeda tentang istilah ini ada dalam literatur dan terdapat kebutuhan untuk mempelajari berbagai aplikasi, tantangan, dan manfaat dari crowdsourcing (Riccardi, 2016). Menurut (Morschheuser, Hamari, Koivisto, \& Maedche, 2017) banyak organisasi menggunakan crowdsourcing sebagai cara untuk menemukan berbagai tugas yang harus dilakukan oleh "kerumunan", sekelompok orang yang dapat dijangkau melalui Internet. Tujuan utama crowdsourcing adalah penghematan biaya atau

Teknologi Informasi dan Komunikasi 
kemungkinan untuk menangani tugas yang sulit dilakukan tanpa dukungan manusia (Morschheuser et al., 2017).

Menurut Guo Tang \& Zhang (2017) dalam crowdsourcing perpaduan semantik media sosial menghadapi tantangan baru, seperti berikut ini: (1) Sumber pengetahuan, dimana informasi media sosial diperoleh dari saluran yang berbeda, seperti sensor, generasi program, generasi pengguna, dan sumber bersama lainnya. (2) Heterogenitas penyimpanan, dimana semantik media sosial berasal dari perpaduan silang antara bentuk, termasuk teks, gambar, audio, dan video, yang tidak menggunakan format penyimpanan yang sama. (3) Ekspresi multimodal, dimana data semantik yang diperoleh di lingkungan crowdsourcing memiliki kemampuan untuk menyampaikan pengetahuan. Namun, karena kompleksitas data, ada sejumlah masalah dengan mode data semantik yang berbeda saat dianalisis, seperti ekspresi spasial multi fitur, multi korelasi, dan sejumlah besar noise. (4) Sosialisasi diseminasi, dimana informasi semantik tidak dipertimbangkan dalam proses diseminasi. Singkatnya, komputasi berbasis crowdsourcing menyediakan cara yang layak untuk menggabungkan semantik secara efisien, namun menemukan banyak masalah karena karakteristik di atas. Ontologi Crowdsourcing memiliki delapan konsep yang dapat dimanfaatkan manajer untuk mengelola aktivitas crowdsourcing. Ontologi mencakup konsep keterbukaan, platform, manajemen, sumber daya, kompensasi, tugas, fokus, dan kedewasaan. Konsep ini mempengaruhi hasil akhir dan nilai yang diterima perusahaan dari aktivitas crowdsourcing (Sivula \& Kantola, 2015).

\section{METODE}

Pengabdian kepada masyarakat ini dimulai dengan pembuatan Portal iBudaya.id. Selanjutnya setelah melalui beberapa kali pengujian, akhirnya Portal iBudaya.id siap diimplemtasikan di tengah masyarakat.

Pembangunan portal pengenalan budaya Indonesia dimulai dari studi pustaka berkenaan mengenai trend multimedia yang cocok dengan portal budaya ini.
Selain itu diperlukan juga pembelajaran / survey mengenai user interface yang sesuai dengan minat masyarakat Indonesia, khususnya generasi muda yang nantinya akan aktif di dalam portal budaya tersebut. Tahapan berikutnya setelah mempelajari teori dan studi lapangan, maka langkah selanjutnya adalah menganalisis dan mendesain portal budaya. Hasil desain yang telah rampung akan diimplementasikan ke dalam bentuk portal multimedia.

Fokus pengabdian kepada masyarakat di tahap kedua lebih kepada isian konten yang perlu diperhatikan dan dikelola dengan baik. Karena walaupun portal sudah memiliki fitur-fitur yang canggih dan menarik, tetap memerlukan isian / konten agar dapat memberikan wawasan budaya bagi para penggunannya kelak. Pengisian konten ini menggunakan teknik crowdsourcing dimana dalam penggunaan teknik ini perlu mengembangkan interface dengan perangkat mobile (smartphone).

Di tahap terakhir lebih bersifat sosialisasi atas apa yang telah dikerjakan di tahap pertama dan kedua. Apalah arti sebuah portal website bila tidak ada konten yang dikelola. Oleh karena itu fokus utama di tahap ini adalah mempromosikan kepada masyarakat untuk isian konten budaya dalam portal. Font yang digunakan adalah Times New Roman 11 poin, normal, spasi tunggal, after 6 pt dan diketik rapi rata kiri kanan (justify).

\section{HASIL DAN PEMBAHASAN}

Fitur-fitur iBudaya.id meliputi: Registrasi dan Login; Upload Dokumen; Publish dan Simpan; Searching dan Advanced Searching; serta Detil User.

Selain itu, konten di dalam iBudaya.id dikelompokkan ke dalam kategori nilai budaya menurut provinsi. Untuk nilai budaya yang sudah melintasi provinsi, maka disediakan kategori Nasional. Hal ini dimaksudkan untuk mempermudah masyarakat dalam mencari nilainilai budaya yang diminati atau ingin dilihat. ibudaya.id.

Berikut ini adalah tampilan Portal Teknologi Informasi dan Komunikasi 


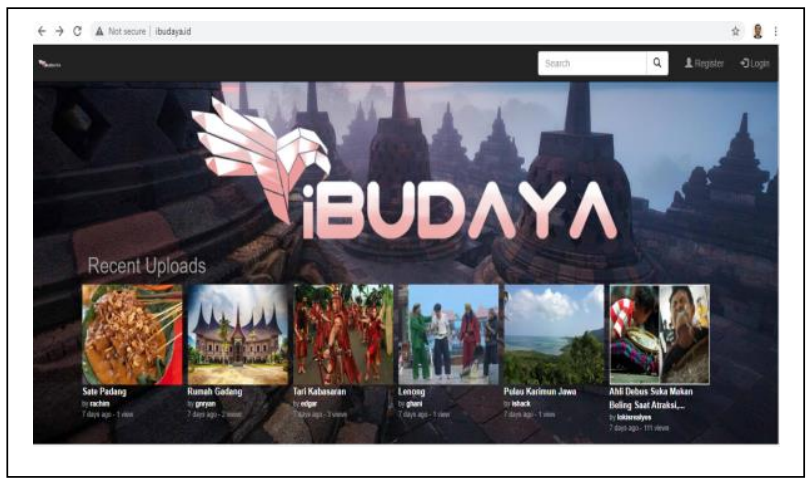

Gambar 1. Tampilan Homepage dari ibudaya.id

Dari tampilan pertama ini, selanjutnya seorang user disarankan untuk melakukan Registrasi, agar untuk selanjutnya dapat mengunggah konten. Adapun Menu Registrasi ada di bagian kanan atas layar. Apabila tidak melakukan Registrasi, maka seorang user hanya dapat melihatlihat konten yang ada di Portal iBudaya tersebut.

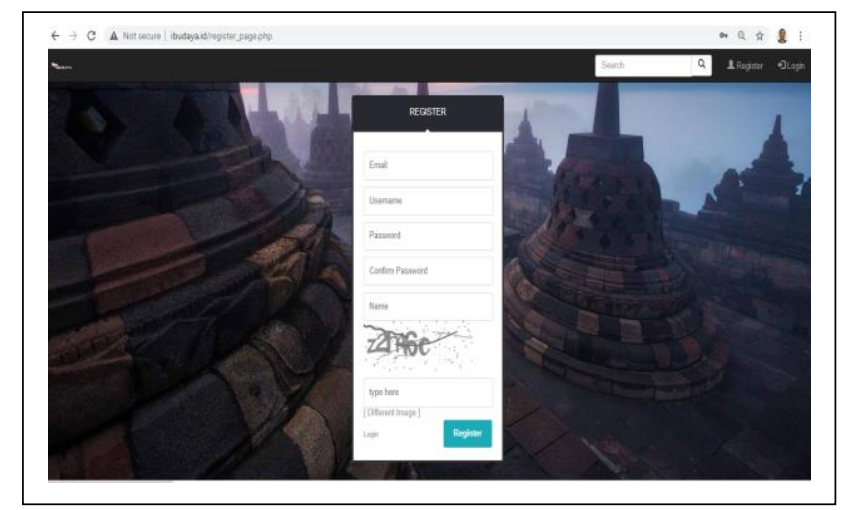

Gambar 2. Tampilan Halaman Registrasi.

Setelah melakukan Registrasi, maka seorang user akan mendapat notifikasi melalui email, berisi nama user (user id) dan password-nya. Adapun nama user dan password tersebut dipilih sendiri oleh user tersebut.

Setelah proses Registrasi selesai, selanjutnya user dapat melakukan Login dengan cara meng-klik Menu Login. Lalu user tersebut mengisi nama user dan password. Dengan demikian selanjutnya user tersebut dapat melakukan aktivitas penuh, seperti mengunggah konten berupa video, musik, foto, dan cerita teks, bahkan slide power point.

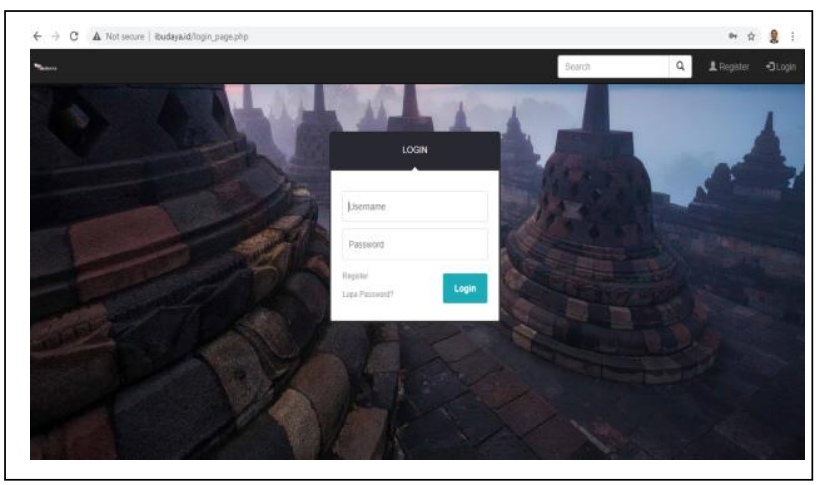

Gambar 3. Tampilan Halaman Login

Adapun jenis konten yang dapat diunggah meliputi nilai-nilai budaya dan kearifan lokal sebagai berikut: upacara adat, pakaian adat, legenda/cerita raksyat, permainan tradisional, alat musik, rumah adat, senjata tradisional, peralatan/perkakas tradisional, pemandangan alam/obyek wisata, peta wilayah, tari-tarian daerah, lagu-lagu daerah, kerajinan, kuliner daerah, serta flora dan fauna daerah.

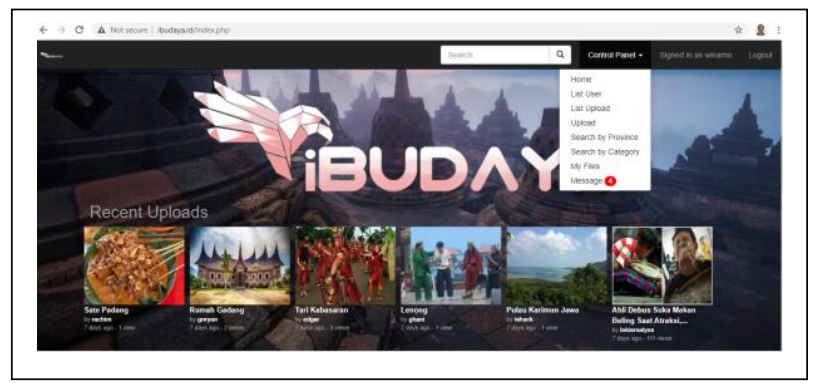

Gambar 4. Tampilan halaman Control Panel

Menu User berupa Conrol Panel, berisi Menu Home, List User, List Upload, Upload, Search By Province, Search By Category, My Files, Message.

Apabila user meng-klik menu Home, maka akan ditampilkan halaman Home seperti pada Gambar 1.

Teknologi Informasi dan Komunikasi 
Apabila user meng-klik menu List User, maka akan ditampilkan daftar para user yang sudah melakukan Registrasi ke iBudaya.id.

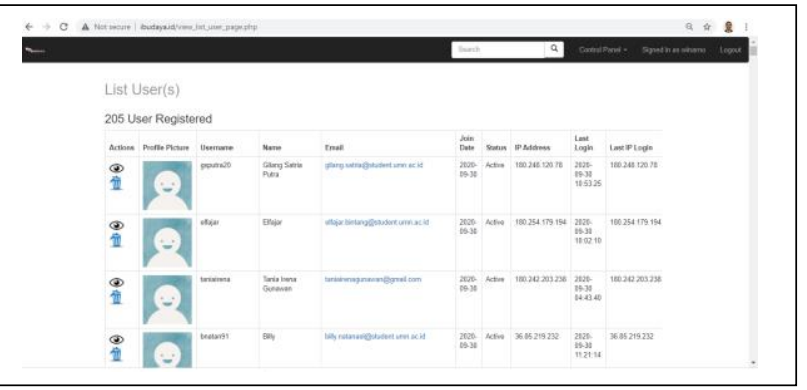

Gambar 5. Tampilam Menu List User.

Selanjutnya apa bila user meng-klik menu List Uploads, maka akan muncul file-file yang sudah diunggah oleh para user. Dalam hal ini semua file yang diunggah akan ditampilkan, dan user dapat melakukan scrolling untuk melihat file-file tersebut.

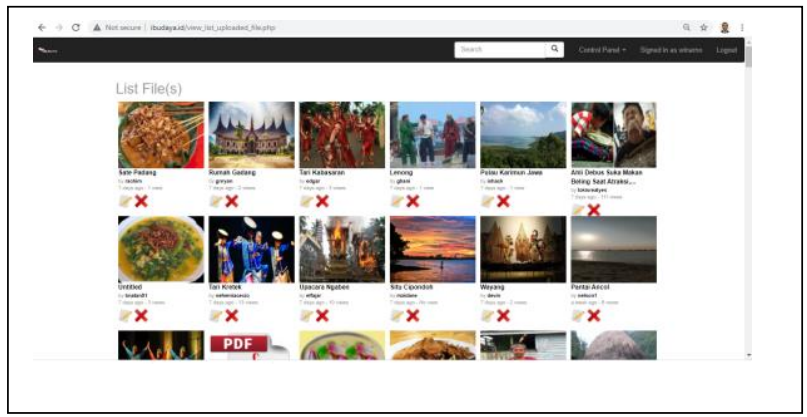

Gambar 6. Tampilan Menu List Uploads.

Apabila user meng-klik Menu Upload, maka akan muncul tampilan sebagai berikut:

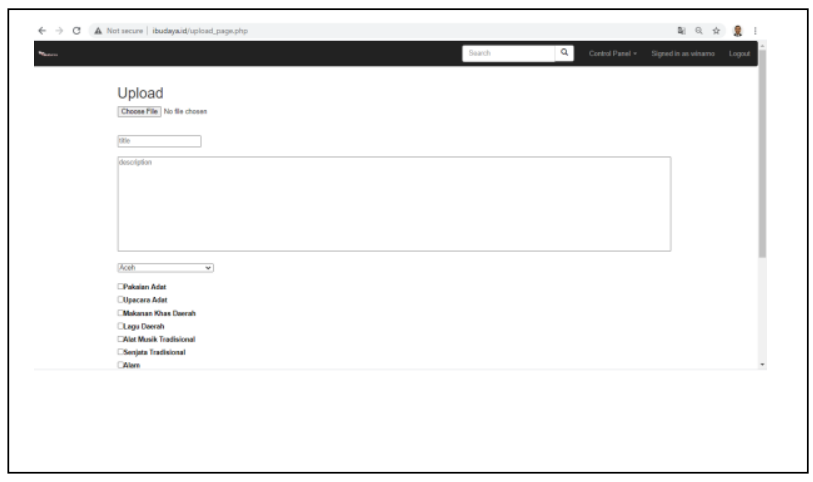

Gambar 7. Tampilan Menu Unggah Konten
Untuk mengunggah suatu konten maka user perlu malakukan hal-hal sebagai berikut: 1) memilih file yang akan diunggah (choose file). 2) Menetapkan judul konten yang diunggah tersebut. 3) Menulis deskripsi atau keterangan tentang konten tersebut, mengenai apa. 4) Memilih asal provinsi dari konten tersebut. 5) Memilih kategori konten dengan cara mencontreng kategori (misalnya Pakaian Adat, Upacara Adat, dan sebagainya). 6) Meng-klik Submit setelah selesai mengisi data di atas.

Selanjutnya, apabila seorang user ingin mencari suatu konten, maka user dapat meng-klik Menu Search By Province atau Menu Search By Category.

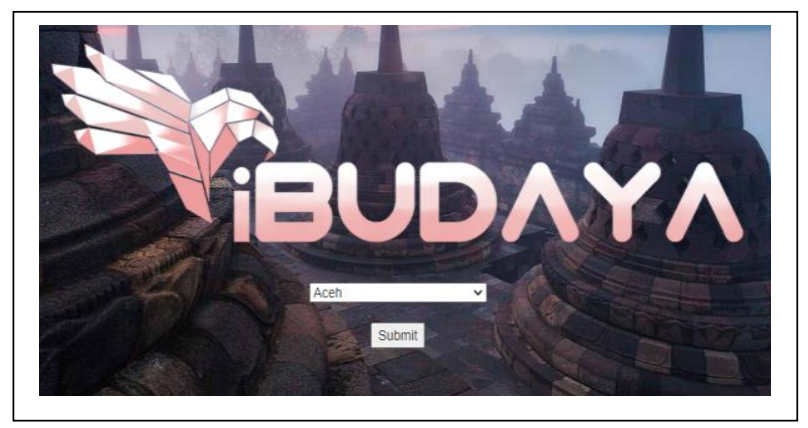

Gambar 8. Tampilan Menu Search By Province.

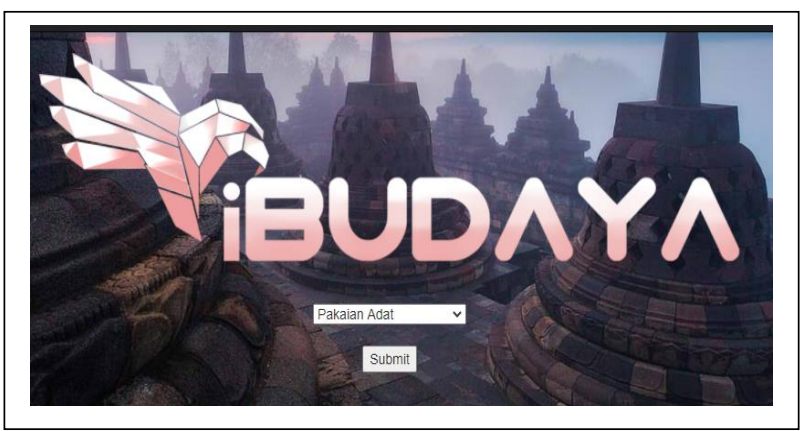

Gambar 9. Tampilan Menu Search By Province.

Apabila user ingin mengetahui apa saja filefile yang pernah diunggah ke iBudaya.id, maka user dapat meng-klik Menu My Files. 


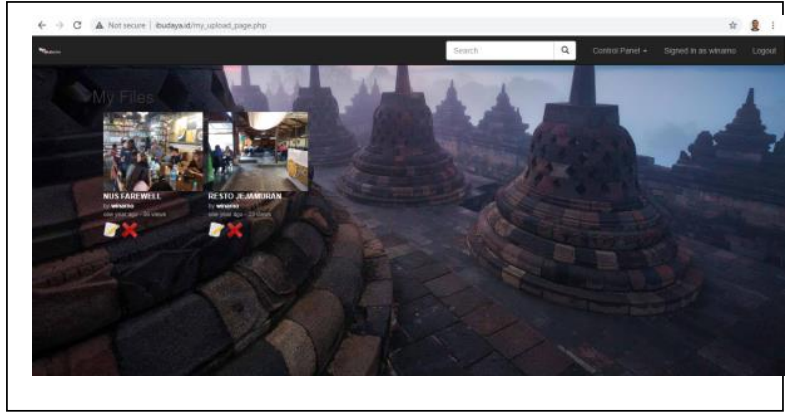

Gambar 10. Tampilan Menu My Files.

Dan apabila user ingin berkomunikasi dengan user lain, maka user dapat meng-klik Menu Messages.

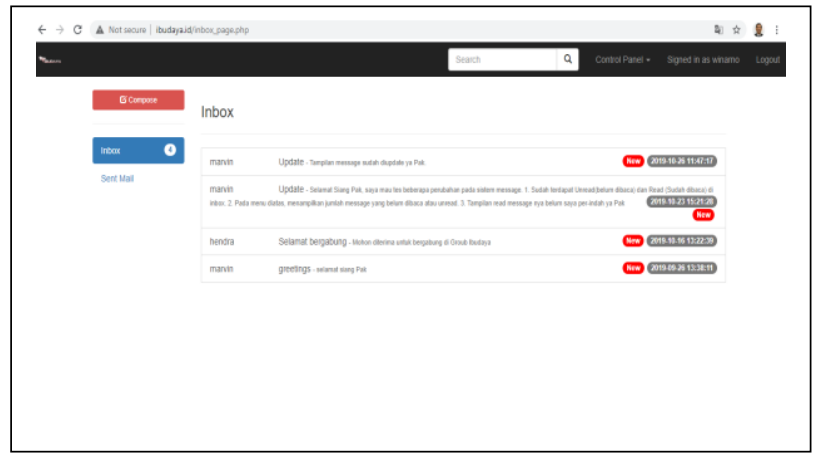

Gambar 11. Tampilan Menu Messages.

Di dalam Menu Messages terdapat fitur sebagai berikut: 1) Compose, yaitu fitur untuk untuk menulis message baru; 2) Inbox, yaitu kotak surat masuk; dan 3) Sent, yaitu kotak surat keluar.

\section{KESIMPULAN}

Implementasi Portal iBudaya.id telah berhasil dilakukan. Hingga saat ini terdapat sekitar 200 user yang telah mendaftar, dan pada umumnya para user tersebut telah mengunggah konten-konten yang menarik. Seiring perjalanan waktu, dan didukung upaya-upaya promosi, diharapkan Portal iBudaya.id ini akan semakin populer dan dibutuhkan oleh masyarakat.
Dengan adanya portal atau website iBudaya.id ini, maka diharapkan masyarakat dapat mengunggah konten-konten tentang budaya Indonesia, sehingga nilai-nilai budaya dan kearifan lokal Bangsa Indonesia dapat dikenal oleh masyarakat luas di dalam negeri maupun di luar negeri.

Portal iBudaya dapat ditingkatkan fiturfiturnya, sehingga semakin menarik bagi masyarakat. Dengan demikian portal iBudaya ini dapat bersaing dengan portal-portal media sosial yang lain, seperti Instagram, Youtube, dan sebagainya.

\section{UCAPAN TERIMAKASIH}

Kegiatan pengabdian kepada masyarakat ini merupakan penerapan hasil penelitian Hibah PTUPT (Penelitian Terapan Unggulan Perguruan Tinggi 2018-2019 dengan Kontrak Penelitian No. 225/SP2H/LT/DRPM/2019.

\section{REFERENSI}

A. Majchrzak and A. Malhotra, "Towards an information systems perspective and research agenda on crowdsourcing for innovation," J. Strateg. Inf. Syst., vol. 22, no. 4, pp. 257-268, 2013.

A. Sivula and J. Kantola, "Ontology Focused Crowdsourcing Management," Procedia Manuf., vol. 3, no. Ahfe, pp. 632-638, 2015.

B. Morschheuser, J. Hamari, J. Koivisto, and A. Maedche, "Gamified Crowdsourcing: Conceptualization, Literature Review, and Future Agenda," Int. J. Hum. Comput. Stud., vol. forthcomin, 2017.

E. Gregori, A. Importa, L. Lenzini, V. Luconi, N. Redini, and A. Vecchio, "Smartphone-based crowdsourcing for estimating the bottleneck capacity in wireless networks," J. Netw. Comput. Appl., vol. 64, pp. 62-75, 2016.

F. Pfarr, M. Chowanetz, and A. Winkelmann, Critical success factors for software-as-a-service adoption, vol. 46, no. 9. IFAC, 2013.

G. Von Krogh, "How does social software change knowledge management? Toward a strategic research agenda," J. Strateg. Inf. Syst., vol. 21, no. 2, pp. 154-164, 2012.

Teknologi Informasi dan Komunikasi 
I. van de Weerd, I. S. Mangula, and S. Brinkkemper, "Adoption of software as a service in Indonesia: Examining the influence of organizational factors," Inf. Manag., vol. 53, no. 7, pp. 915-928, 2016.

J. Goncalves, S. Hosio, M. Vukovic, and S. Konomi, "Mobile and situated crowdsourcing," Int. J. Hum. Comput. Stud., vol. 102, no. xxxx, pp. 1-3, 2017.

J. Rodrigues, P. Ruivo, and T. Oliveira, "Software as a Service Value and Firm Performance - A literature Review Synthesis in Small and Medium Enterprises," Procedia Technol., vol. 16, pp. 206211, 2014.

J. Zhao, P. O. De Pablos, and Z. Qi, "Enterprise knowledge management model based on China's practice and case study," Comput. Human Behav., vol. 28, no. 2, pp. 324-330, 2012.

K. Guo, Y. Tang, and P. Zhang, "CSF: Crowdsourcing semantic fusion for heterogeneous media big data in the internet of things," Inf. Fusion, vol. 37, pp. 77-85, 2017.

Kompasiana.com, "Agnes MO, Arab dan Budaya Kita," 2016. [Online]. Available: http://www.kompasiana.com/faizabdalla31/agnesmo-arab-dan-budayakita_56abab38a723bd43048b45ca.

Liputan6, "Renita Angkat Budaya Indonesia yang Kaya," 2017. [Online]. Available: http://citizen6.liputan6.com/read/2877170/renitaangkat-budaya-indonesia-yang-kaya.

Liputan6, "Irfan Hakim Sayangkan Generasi Muda Gengsi dengan Budaya Asli Indonesia," 2016. [Online]. Available: http://video.liputan6.com/read/2416841/irfanhakim-sayangkan-generasi-muda-gengsi-denganbudaya-asli-indonesia.

L. Wu, S. Kumar Garg, and R. Buyya, "SLA-based admission control for a Software-as-a-Service provider in Cloud computing environments," $J$. Comput. Syst. Sci., vol. 78, no. 5, pp. 1280-1299, 2012.

L. Yuan, C. Xi, and W. Xiaoyi, "Evaluating the readiness of government portal websites in China to adopt contemporary public administration principles," Gov. Inf. Q., vol. 29, no. 3, pp. 403-412, 2012.

M. Safran and D. Che, "Real-time recommendation algorithms for crowdsourcing systems," Appl. Comput. Informatics, vol. 13, no. 1, pp. 47-56, 2017.

M. T. Riccardi, "The power of crowdsourcing in disaster response operations," Int. J. Disaster Risk Reduct., vol. 20, no. October, pp. 123-128, 2016.

Republika.co.id, “Antropolog: Teknologi Efektif untuk Politik Kebudayaan,” 2017. [Online]. Available: http://nasional.republika.co.id/berita/nasional/daer $\mathrm{ah} / 17 / 03 / 25 /$ ondksv284-antropolog-teknologiefektif-untuk-politik-kebudayaan.

R. Nowacki and K. Bachnik, "Innovations within knowledge management," J. Bus. Res., vol. 69, no. 5, pp. 1577-1581, 2016.

R. Rezaei, T. K. Chiew, S. P. Lee, and Z. Shams Aliee, "A semantic interoperability framework for software as a service systems in cloud computing environments," Expert Syst. Appl., vol. 41, no. 13, pp. 5751-5770, 2014.

Zonalima, "Mendagri: Yang Kita Hadapi Saat ini Adalah Krisis Budaya," 2016. [Online]. Available: http://www.zonalima.com/artikel/9633/MendagriYang-Kita-Hadapi-Saat-ini-Adalah-KrisisBudaya/. 